\title{
Using cave deposits as geologic tiltmeters: Application to postglacial rebound of the Sierra Nevada, California
}

\author{
Darryl E. Granger \\ Department of Earth and Atmospheric Sciences, Purdue University, West Lafayette, Indiana, USA
}

Greg M. Stock

Department of Earth Sciences, University of California, Santa Cruz, California, USA

Received 2 September 2004; accepted 15 October 2004; published 19 November 2004.

[1] Secondary calcite shelfstone deposits in caves can be used to precisely measure tilting over geologic timescales. Calcite deposited along the edges of former pools can be surveyed to within a single millimeter, and can be dated using uranium-series disequilibrium. Two caves in the southern Sierra Nevada, California, contain tilted calcite deposits of glacial age. A third cave contains a similar but untilted deposit of older interglacial age. The cave deposits record glacio-isostatic rebound of the Sierra Nevada, following melting of an ice cap $\sim 15,000$ years ago. Models of crustal flexure beneath mapped ice thickness reproduce the observed tilting with an effective elastic thickness $\left(\mathrm{T}_{\mathrm{e}}\right)$ of approximately $5 \mathrm{~km}$. INDEX TERMS: 1206 Geodesy and Gravity: Crustal movementsinterplate (8155); 1035 Geochemistry: Geochronology; 1824 Hydrology: Geomorphology (1625); 8164 Tectonophysics: Stresses - crust and lithosphere; 9820 General or Miscellaneous: Techniques applicable in three or more fields. Citation: Granger, D. E., and G. M. Stock (2004), Using cave deposits as geologic tiltmeters: Application to postglacial rebound of the Sierra Nevada, California, Geophys. Res. Lett., 31, L22501, doi:10.1029/ 2004GL021403.

\section{Introduction}

[2] Measuring tilt rates is important for characterizing the behavior of the earth's crust in response to tectonic stresses, as well as loading and unloading due to glaciers, lakes, and erosion and sediment deposition. Tilting over short timescales can be measured geodetically, either by resurveying or by Global Positioning Systems. Accurate measurements of tilt over longer timescales require an identifiable surface of known initial orientation, usually marks left by a body of water such as a lake or ocean. Although not previously used in this manner, caves often provide an ideal situation for reconstructing tilt, because bedrock rooms and depressions may contain standing water that is oversaturated with respect to calcite; this mineral crystallizes along pool edges in a characteristic form called shelfstone [Hill and Forti, 1997]. Cave pools are ephemeral, dependent on particular seeps and drips from the surface. If those sources of water cease to flow, then pools will dry, leaving a horizontal surface of shelfstone and other calcite speleothem to mark its earlier presence. Shelfstone edges can be accurately surveyed, and, in many

Copyright 2004 by the American Geophysical Union. 0094-8276/04/2004GL021403\$05.00 cases, the original water surface identified to within a single millimeter. In addition, the shelfstone can be dated using uranium-series (U-series) disequilibrium to determine the time of calcite deposition, over timescales up to $\sim 400,000$ years [Dorale et al., 2004].

[3] The precision of a tilt measurement from a cave can be comparable to that for a large lake or river. Because the pool's edge can be surveyed vertically to within a millimeter, a pool that is only five meters across can be used to detect gradients as small as 0.0002. Lake shorelines are typically only level to within 2 meters [e.g., Adams et al., 1999]. Obtaining similar precision from such a shoreline would require measurements over a distance of 10 kilometers. To illustrate the sensitivity of the shelfstone method and its application to geologic problems, we report here the postglacial rebound of the Sierra Nevada, California.

\section{Postglacial Rebound of the Sierra Nevada}

[4] Postglacial rebound can provide important constraints on the behavior of the lithosphere, but has seldom been applied to mountain ranges. Tilting of mountain ranges is small and difficult to measure because the load due to an ice cap is narrow and of variable thickness. Moreover, there are few surfaces or deposits preserved in montane environments that can be used to reconstruct tilt.

[5] The Sierra Nevada mountains are a large crustal block broken on the east by Basin and Range faulting and tilted westward about a hinge line in the eastern Great Valley (Figure 1) [e.g., Bateman and Wahrhaftig, 1966; Unruh, 1991; Wakabayashi and Sawyer, 2001]. The range was extensively glaciated during the last glacial maximum (Figure 1), and was rapidly deglaciated at approximately 15,000 years ago [Clark et al., 1995]. Although lithology of the southern Sierra Nevada is primarily plutonic, certain marble-bearing roof pendants on the western slope of the range are riddled with caves. We identified three caves that contain shelfstone suitable for tilt measurements (Figure 1). Our criteria for selection were that (1) the shelfstone extend over a length greater than 1 meter, (2) the shelfstone be precipitated onto bedrock, not sediment, (3) there be no visible cracks in the cave walls that might indicate local tilting, and (4) the shelfstone not be covered by younger deposits. Two of our measured caves are located within $1 \mathrm{~km}$ of each other (Crystal Cave and Weis Raum), while the third cave is located $20 \mathrm{~km}$ to the south (Soldiers Cave). All three 


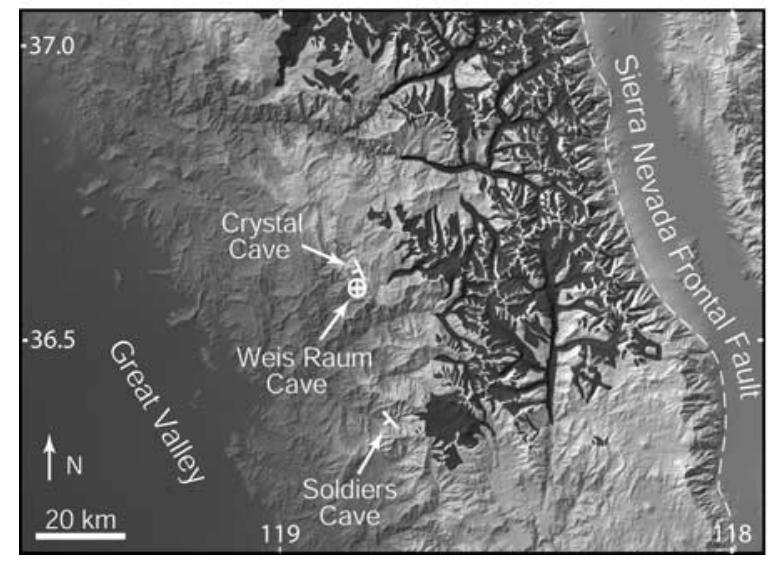

Figure 1. Map of the southern Sierra Nevada, California, showing cave locations (marked by strike and dip symbols) and the extent of Tioga (MIS 2) glaciation ca. 20,000 years B.P. Glacial extent based on mapping by [Matthes, 1965; Wahrhaftig and Birman, 1965].

caves are just west of the maximum extent of glaciation (Figure 1).

\section{Measurements}

[6] We surveyed the shelfstone deposits using a rotating laser level (horizontal to within $0.3 \mathrm{~mm}$ at 30 meters), using digital calipers to measure vertical distance from the laser beam to the rim of the shelf at multiple locations within each former pool. Each author made measurements independently; all measurements agreed to within $0.5 \mathrm{~mm}$, with a root-mean-square difference of $0.22 \mathrm{~mm}$. Plan surveys of the shelfstones were made with compass and tape. A plane was fit to the measurements using least squares; all survey data fit the planes to within $0.45 \mathrm{~mm}$, which is comparable to our measurement uncertainty. Orientations of the planes are given in Table 1, with uncertainties estimated by $\chi^{2}$ variation [Bevington, 1969].

[7] Duplicate shelfstone samples were collected for dating each pool. Approximately $1 \mathrm{~g}$ of each sample was crushed, handpicked for clean calcite, and dissolved in $8 \mathrm{~N}$ $\mathrm{HNO}_{3}$. Samples measured by thermal ionization mass spectrometry (TIMS) were spiked with ${ }^{229} \mathrm{Th}$ and ${ }^{233} \mathrm{U}$ tracers. $\mathrm{U}$ and Th were co-precipitated with $\mathrm{Fe}(\mathrm{OH})_{3}$ and purified by ion-exchange chemistry following [Edwards et al., 1987]. Purified U and Th were loaded onto single zonerefined Re filaments with colloidal graphite and run on a VG 54/WARP TIMS. Measured ${ }^{234} \mathrm{U} /{ }^{235} \mathrm{U}$ for SRM U010 was $0.00538 \pm 0.5 \%$. U/Th ratios for the Soldiers Cave sample were measured using inductively coupled plasma mass spectrometry (ICP-MS). An aliquot of this sample was spiked with ${ }^{229} \mathrm{Th}$ and ${ }^{236} \mathrm{U}$, and $\mathrm{U}$ and Th concentrations were measured on a Thermo Finnigan Element 1 ICP-MS by isotope dilution. Purified $U$ and Th were then measured on a Thermo Finnigan Neptune multi-collector ICP-MS by bracketing with UCSC standards and correcting for instrument bias with NIST standards. We corrected for initial ${ }^{230} \mathrm{Th}$ using a detrital $\left({ }^{230} \mathrm{Th} /{ }^{232} \mathrm{Th}\right)$ ratio of $0.8 \pm 0.8(2 \sigma)$ typical of upper continental crust; given relatively high $\left({ }^{230} \mathrm{Th} /{ }^{232} \mathrm{Th}\right)$ ratios, the amount of correction is small and does not affect our interpretation of glacial vs. interglacial ages. Corrected sample ages are reported in Table 1.

\section{Results and Modeling of Postglacial Rebound}

[8] Two caves (Crystal Cave and Soldiers Cave) contain shelfstone deposits that are now tilted. Both of the shelfstones were deposited during or immediately after the last glacial maximum (Tioga glaciation [Blackwelder, 1931], marine isotope stage (MIS) 2; Table 1), when an ice cap averaging 200-400 m thick covered much of the Sierra Nevada above $3500 \mathrm{~m}$ (Figure 1) [Wahrhaftig and Birman, 1965]. The two tilts are similar in both strike and dip (Table 1). We infer that these glacial age pools, whose shelfstone was deposited during the peak of ice loading, are now tilted southwest due to isostatic rebound of the crest following deglaciation. The third cave (Weis Raum) contains an older shelfstone deposit that is level to within measurement uncertainty $(\sim 0.5 \mathrm{~mm}$ over a 4.5 meter pool diameter). This older deposit dates to the last interglacial (MIS 5e; Table 1). Weis Raum Cave is located within $1 \mathrm{~km}$ of Crystal Cave, with no known faults between the two [Sisson and Moore, 1994; unpublished mapping]. The absence of tilt in the older interglacial deposit is strong confirmation that the tilted deposits are of glacio-isostatic origin. If tilt were due either to local faulting or regional tectonics, then the older deposit should record at least as much tilt as the younger deposits. If tilt were due to postglacial isostatic rebound, then pools of interglacial age would exhibit no tilt at all, as observed. As expected, recent shelfstone deposits in cave passages within the modern flood zone (i.e., Holocene age) are not tilted.

[9] The measured tilts can be used to estimate the effective elastic thickness $\left(\mathrm{T}_{\mathrm{e}}\right)$ of the crust, if the ice loading can be well constrained. Tioga-age glaciation of the southern Sierra Nevada has been accurately mapped for a portion of our study area [Matthes, 1965; J. H. Birman, Glaciation of parts of Sequoia and Kings Canyon National Parks, Sierra Nevada, California, report to Sequoia National Park, 1962; J. Clague et al., Glacial geology in the Kern Canyon drainage, Sierra Nevada, California, unpublished Report to Sequoia National Park]. We used these detailed maps of glacial coverage and estimated ice thickness from topographic maps and the glacial extent of [Wahrhaftig and Birman, 1965] where detailed maps were unavailable. Ice thickness was estimated on a $1 \mathrm{~km}$ grid, extending from the southernmost glaciers, at a latitude $17 \mathrm{~km}$ south of Soldiers cave, to a latitude $40 \mathrm{~km}$ north of Crystal Cave $(70 \mathrm{~km}$ total). We modeled flexure of the mountain range due to ice loading as that of a thin elastic plate overlying an inviscid fluid. We considered the plate to have a uniform elastic thickness; although spatial variations in elastic thickness in this region are likely [Adams et al., 1999; Lowry et al.,

Table 1. Shelfstone Tilt Measurements and U-Series Ages

\begin{tabular}{llc}
\hline \multicolumn{1}{c}{ Location } & \multicolumn{1}{c}{ Attitude of Tilt } & \multicolumn{1}{c}{ Age (yr) } \\
\hline Aragon Room, & STR $=320^{\circ} \pm 13^{\circ}$ & $14,725 \pm 765$ \\
Soldiers Cave & DIP $=0.99 \pm 0.35 \mathrm{~mm} / \mathrm{m} \mathrm{SW}$ & \\
Organ Balcony, & STR $=336^{\circ} \pm 46^{\circ}$ & $21,320 \pm 430$ \\
Crystal Cave & DIP $=1.39 \pm 0.13 \mathrm{~mm} / \mathrm{m} \mathrm{SW}$ & \\
Pool Room, & $\begin{array}{l}\text { No detectable tilt } \\
(<0.1 \mathrm{~mm} / \mathrm{m})\end{array}$ & $116,300 \pm 2,600$ \\
Weis Raum Cave & $(<$.
\end{tabular}




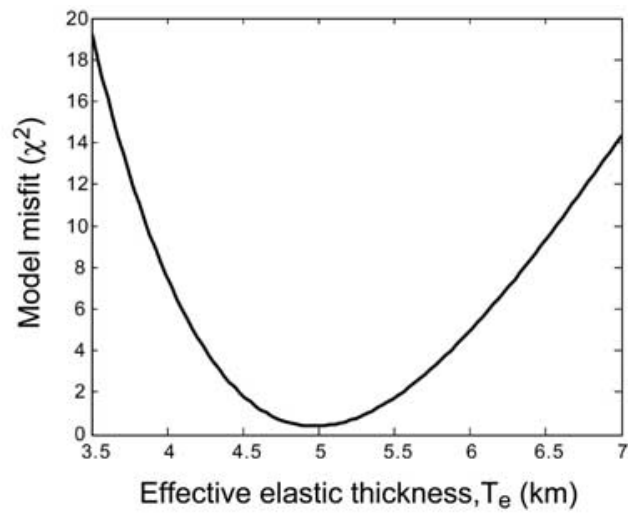

Figure 2. Model misfit as a function of effective elastic thickness, showing a good fit to the data for $T_{e}=5 \mathrm{~km} . \chi^{2}$ deviations are scaled by measurement uncertainties in both strike and dip for Soldiers Cave and Crystal Cave (Table 1).

2000], our sparse data do not justify such a complex model. The ice load was modeled as a distribution of point loads on a $1 \mathrm{~km}$ grid, using 3171 non-zero loads. We solved for displacement and tilting using Kelvin-Bessel functions [Watts, 2001], assuming an ice density of $900 \mathrm{~kg} \mathrm{~m}^{-3}$, a density of the displaced fluid mantle of $3300 \mathrm{~kg} \mathrm{~m}^{-3}$, a Young's modulus of $7 \times 10^{10} \mathrm{~Pa}$, and a Poisson's ratio of 0.25 . The flexural response to the ice load was calculated for a range of $T_{e}$ at each cave's location; tilt values from the model are shown in Figure 2.

[10] Our flexure model accurately reproduces the strikes and dips of both caves to well within measurement uncertainties. Our best-fit value for $T_{e}$ is $5 \mathrm{~km}$, obtained by minimizing $\chi^{2}$ deviations in both strike and dip (Figure 2).

\section{Comparison to Previous Work}

[11] There are few previous estimates for the effective elastic thickness of the Sierra Nevada crust. [Small and Anderson, 1995] estimated the flexural rigidity by modeling the tilt and subsidence of two 8-10 million-year-old sedimentary horizons in the Sierra Nevada foothills and Great Valley, and obtained a $T_{e}$ value of approximately $20 \mathrm{~km}$. The marker beds of [Small and Anderson, 1995] are both significantly older than, and west of, our cave deposits near the range crest, and so these measurements are difficult to directly compare. Previous work measuring the coherence of Bouguer gravity anomalies and topography [Bechtel, 1989] for a broad region including the southern Sierra Nevada, Great Valley, and Coast Ranges to the west, obtained a value for $T_{e}$ of $7 \mathrm{~km}$. Because this value is averaged over a large area, it is likely an overestimate for the southern Sierra Nevada, and is consistent with our estimate from postglacial rebound. An earlier estimate by [Chase and Wallace, 1986] of $\mathrm{T}_{\mathrm{e}}=50 \mathrm{~km}$ was based on the existence of a thick mountain root, and is not valid for the modern range, which no longer has such a root [Wernicke et al., 1996].

[12] Our value of $T_{e}$ for the Sierra Nevada crust is lower than or comparable to many estimates for the extended crust of the Basin and Range. Rebound of pluvial lakes reveals $T_{e}$ values of $20-30 \mathrm{~km}$ in the Lahontan basin to the north [Adams et al., 1999], and approximately $25 \mathrm{~km}$ in the
Bonneville basin, $600 \mathrm{~km}$ to the northeast [Bills et al., 1994]. The coherence of Bouguer gravity anomalies and topography reveals a lower $T_{e}$ of $4-5 \mathrm{~km}$ for the Basin and Range [Armstrong and Watts, 2001; Stewart and Watts, 1997; Ruppert et al., 1998], very similar to our estimate for the Sierra Nevada.

[13] Disparate values for $T_{e}$ are often explained in terms of viscous relaxation times. Short-lived loads such as lakes and glaciers would correspond to a higher $T_{e}$ than long-lived loads such as sedimentary basins and topography. This explanation cannot reconcile the low $\mathrm{T}_{\mathrm{e}}$ values for the Sierra Nevada from both glacio-isostatic rebound and gravitational admittance with the relatively high $\mathrm{T}_{\mathrm{e}}$ obtained from displacement of the 8-10 million-year-old sedimentary horizons [Small and Anderson, 1995]. One possible explanation is that the Sierra Nevada simultaneously exhibits a low $T_{e}$ near the range crest and a high $T_{e}$ in the Great Valley. The Andes are often considered to be an analog for the early Sierra Nevada, and show similar variability in $\mathrm{T}_{\mathrm{e}}$, with values as low as $5 \mathrm{~km}$ near the range crest, but more commonly $25-50 \mathrm{~km}$ on the mountain flanks [Stewart and Watts, 1997].

\section{Summary}

[14] This is the first estimate of $T_{e}$ for the Sierra Nevada based on measured tilt, and to our knowledge is the first measurement of isostatic rebound due to alpine glaciation. It has previously been difficult to measure glacio-isostatic rebound in mountain belts, because there are seldom lakes large enough to record deformation, lake shorelines are rarely preserved, and most lakes post-date glaciation. Shelfstone deposits in caves offer an alternative method that is likely to be suitable in many places around the world, wherever karst is found. This new tool for measuring isostatic rebound should help lead to additional constraints on the rheology and elastic behavior of Earth's crust in other active tectonic environments.

[15] Acknowledgments. Supported by NSF CAREER grant EAR0092459 to DEG. We thank D. Fabel and C.S. Riebe for field assistance, P. Holden, J. Aggarwal, and D. Sampson for analytical assistance, and J. Despain and Sequoia National Park for permission to work in the caves.

\section{References}

Adams, K. D., S. G. Wesnousky, and B. G. Bills (1999), Isostatic rebound, active faulting, and potential geomorphic effects in the Lake Lahontan Basin, Nevada and California, Geol. Soc. Am. Bull., 111, 1739-1756.

Armstrong, G. D., and A. B. Watts (2001), Spatial variations in $\mathrm{T}_{\mathrm{e}}$ in the southern Appalachians, eastern United States, J. Geophys. Res., 106, 22,009-22,026.

Bateman, P. C., and C. Wahrhaftig (1966), Geology of the Sierra Nevada, in Geology of Northern California, edited by E. H. Bailey, pp. 105-172, Calif. Div. of Mines and Geol., San Francisco.

Bechtel, T. D. (1989), Mechanisms of isostatic compensationin East Africa and North America, Ph.D. thesis, Brown Univ., Providence, R. I.

Bevington, P. R. (1969), Data Reduction and Error Analysis for the Physical Sciences, 336 pp., McGraw-Hill, New York.

Bills, B. G., D. R. Currey, and G. A. Marshall (1994), Viscosity estimates for the crust and upper mantle from patterns of lacustrine shoreline deformation in the Eastern Great Basin, J. Geophys. Res., 99, 22,05922,086 .

Blackwelder, E. (1931), Pleistocene glaciation in the Sierra Nevada and Basin Ranges, Geol. Soc. Am. Bull., 42, 865-922.

Chase, C. G., and T. C. Wallace (1986), Uplift of the Sierra Nevada of California, Geology, 14, 730-733.

Clark, D. H., P. R. Bierman, and P. Larsen (1995), Improving in situ cosmogenic chronometers, Quat. Res., 44, 367-377. 
Dorale, J. A., R. L. Edwards, E. C. Alexander Jr., C. Shen, D. A. Richards, and H. Cheng (2004), Uranium-series dating of speleothems: Current techniques, limits, and applications, in Studies of Cave Sediments: Physical and Chemical Records of Paleoclimate, edited by I. D. Sasowsky and J. Mylroie, pp. 177-197, Kluwer Acad., New York.

Edwards, R. L., J. H. Chen, and G. J. Wasserburg (1987), ${ }^{238} \mathrm{U}_{-}{ }^{234} \mathrm{U}^{230}{ }^{23} \mathrm{Th}-{ }^{232} \mathrm{Th}$ systematics and the precise measurement of time over the past 500,000 years, Earth Planet. Sci. Lett., 81, 175-192.

Hill, C., and P. Forti (1997), Cave Minerals of the World, 463 pp., Natl. Speleological Soc., Huntsville, Ala.

Lowry, A. R., N. M. Ribe, and R. B. Smith (2000), Dynamic elevation of the Cordillera, western United States, J. Geophys. Res., 105, 23,37123,390.

Matthes, F. E. (1965), Glacial reconnaissance of Sequoia National Park California, U.S. Geol. Surv. Prof. Pap., 504-A, 58 pp.

Ruppert, S., M. M. Fliedner, and G. Zandt (1998), Thin crust and active upper mantle beneath the southern Sierra Nevada in the western United States, Tectonophysics, 286, 237-252.

Sisson, T. W., and J. G. Moore (1994), Geologic map of the Giant Forest quadrangle, Tulare County, California, U.S. Geol. Surv. Quad. Map, GQ-1751.

Small, E. E., and R. S. Anderson (1995), Geomorphically driven late Cenozoic rock uplift in the Sierra Nevada, California, Science, 270, $27-280$.
Stewart, J., and A. B. Watts (1997), Gravity anomalies and spatial variations of flexural rigidity at mountain ranges, J. Geophys. Res., $102,5253-5327$

Unruh, J. R. (1991), The uplift of the Sierra Nevada and implications for late Cenozoic epeirogeny in the western Cordillera, Geol. Soc. Am. Bull., $103,1395-1404$

Wahrhaftig, C., and J. H. Birman (1965), The Quaternary of the Pacific Mountain system in California, in The Quaternary of the United States, edited by H. E. Wright Jr. and D. G. Frey, pp. 299-340, Princeton Univ. Press, Princeton, N. J.

Wakabayashi, J., and T. L. Sawyer (2001), Stream incision, tectonics, uplift, and evolution of topography of the Sierra Nevada, California, J. Geol., 109, 539-562.

Watts, A. B. (2001), Isostasy and Flexure of the Lithosphere, 458 pp., Cambridge Univ. Press, New York.

Wernicke, B., et al. (1996), Origin of high mountains in the continents: The southern Sierra Nevada, Science, 271, 190-193.

D. E. Granger, Department of Earth and Atmospheric Sciences, Purdue University, West Lafayette, IN 47907-1397, USA. (dgranger@purdue.edu) G. M. Stock, Department of Earth Sciences, University of California, Santa Cruz, Santa Cruz, CA 95064, USA. 